\title{
Acute lower limb ischemia in an ICU admitted patient diagnosed with covid 19: a case report
}

\author{
Armin Sadeghi ${ }^{1}$ and mohammadreza moslemi ${ }^{1}$ \\ ${ }^{1}$ Tabriz University of Medical Sciences Faculty of Medicine
}

July 22,2021

\begin{abstract}
Thromboembolic events have been reported in hospitalized patient since beginning of the covid 19 pandemic. This study reports an ICU admitted patient with lower extremity arterial thrombosis diagnosed with covid 19.

\section{Introduction}

The corona virus disease 2019, caused by severe acute respiratory syndrome coronavirus 2 (SARS-CoV-2), is a rapidly evolving health crisis. Since beginning of covid 19 pandemic, many cases of thromboembolic events have been reported ${ }^{1,2}$. The Prevalence of thrombosis among patients with covid 19 is not fully established , but studies showed that most of them are venous thromboembolism ${ }^{3}$. Arterial events commonly been reported in the forms of acute coronary syndrome ${ }^{3,4}$. In this study, we report an ICU (intensive care unit) admitted covid19 patient with Iliac and infrainguinal arterial thrombosis.
\end{abstract}

\section{Case presentation}

A 40-year-old male without any past medical history admitted in the covid 19 ICU with complaint of fever, myalgia and progressive dyspnea over 4 days. vital signs in the day of admission revealed blood pressure of $110 / 60 \mathrm{mmhg}$, heart rate of 87 , respiratory rate 25 , low grade fever and oxygen saturation of $85 \%$ on room air. Chest computerized tomography scan (CT scan) showed peripheral bilateral patchy ground glass infiltrations which is suggestive for covid 19 pneumonia and venous blood gas information (ph:7/41 po2:54 mmhg pco2: $35 \mathrm{mmhg}$ hco3:20 mmol/dl) and o2 saturation of $85 \%$ revealed the patient was in moderate to severe acute respiratory distress syndrome (ARDS) according to Berlin ARDS criteria. Initial laboratory evaluations showed: hemoglobin $14 \mathrm{~g} / \mathrm{dl}$, total leukocyte count 9800 per microliter, absolute neutrophil count 7100 per microliter absolute lymphocyte count 2100 per microliter, platelets 330000 per microliter, BUN $28 \mathrm{mg} / \mathrm{dl}$, serum creatinine $0.9 \mathrm{mg} / \mathrm{dl}$, prothrombin time 12s, international normalized ratio $1 \mathrm{~s}$, partial thromboplastin time 38s, lactate dehydrogenase $1200 \mathrm{u} /$ land C-reactive protein was $86 \mathrm{mg} / \mathrm{dl}$. Electrocardiogram showed sinus tachycardia of 106 beats per minute. The patient was started on remdesivir, dexamethasone, heparin for prophylaxis.

On second day of hospitalization, the patient complained about a sudden severe pain in his right leg. On examination, he had profound weakness in the right leg, mild weakness in the left leg, and absent pulses. The findings of laboratory data (complete blood counts and PT, PTT, INR and liver and kidney function tests) were unremarkable. Doppler ultrasonography reported intraluminal thrombus with in the distal part of right common iliac artery. CT angiography showed thrombotic occlusion at right common iliac artery, right external iliac artery and common femoral artery (Fig 1,2).

Lupus anticoagulant antibody, antiphospholipid antibody, anticardiolipin antibodies, anti beta2 glycoprotein, anti-nuclear antibody (ANA), P-ANCA, C-ANCA and c3, c4, CH50 complement level were in normal range. 
The patient was started on therapeutic anticoagulation with unfractionated heparin. Angiography of bilateral iliac and lower extremity arteries showed thrombotic occlusion of right common iliac artery, right external iliac artery, right superficial femoral artery, right popliteal artery and a partial thrombolysis at left common iliac artery.

Revascularization and thrombolysis by injecting tissue plasminogen activator was not sufficient and the patient underwent leg amputation one day after angiography.

\section{Discussion}

Since September 2019 during covid 19 pandemic , many cases of thromboembolic events have been reported $^{1,2}$. The Prevalence of thrombosis among patients with covid 19 is not fully established, but studies showed that most of them are venous thromboembolism ${ }^{3}$. Klok et al., study revealed that the cumulative incidence of a composite outcome of vascular events (acute pulmonary embolism, deep-vein thrombosis, ischemic stroke, myocardial infarction, systemic arterial embolism) was $31 \%$, the incidence of venous thromboembolisms was $27 \%$, and the incidence of arterial events was $3.7 \%$, among patients in the $\mathrm{ICU}^{5}$.

In this study we report an ICU admitted covid 19 patient with iliac and infrainguinal arterial thrombosis. Assessment about vasculitis, antiphospholipid antibody syndrome, systemic lupus erythematosus and another common causes of arterial thrombosis were unremarkable. There are several mechanisms which can explain the correlation of covid 19 disease and thromboembolic events. In severe cases of covid 19, cytokines storm and infection of endothelial cells through angiotensin-converting enzyme 2 protein cause endothelial damage , coagulopathy and complement-induced thrombosis, microangiopathy and thromboembolic events ${ }^{6-8}$. So probably covid 19 can be considered the probable cause of thromboembolism in our patient through these mechanisms.

His study reported a covid 19 patient who developed arterial lower extremity thrombosis leading to acute ischemia and limb amputation. Our case and several reports of thromboembolic events among hospitalized patients of covid19 reveal that health care providers should be aware of life-threatening thromboembolic events associated with covid 19 so that prompt and appropriate intervention can be undertaken.

\section{Acknowledgment}

None

\section{Funding}

This research did not receive any specific grant from funding agencies in the public, commercial, or not-forprofit sectors.

\section{Conflicts of interest}

None

\section{Ethics}

This study was performed according to the principles outlined by the World Medical Association's Declaration of Helsinki on experimentation involving human subjects, as revised in 2000 and has been approved by the ethics committee of the Tabriz University of Medical Sciences.

\section{Author Contributions:}

Armin Sadeghi: The conception and design of the study, Final approval of the version to be submitted

Mohammadreza Moselmi: The conception and design of the study, Drafting the article, Final approval of the version to be submitted

\section{References}


1. Chen N, Zhou M, Dong X, Qu J, Gong F, Han Y, et al. 2020 Epidemiological and clinical characteristics of 99 cases of 2019 novel coronavirus pneumonia in Wuhan, China: a descriptive study. Lancet 395:507-13.

2. Helms J, Tacquard C, Severac F, Leonard-Lorant I, Ohana M, Delabranche X, et al. 2020 High risk of thrombosis in patients with severe SARS-CoV-2 infection: a multicenter prospective cohort study. Intensive Care Med 46:1089-98.

3. Middeldorp S, Coppens M, van Haaps TF, Foppen M, Vlaar AP, Müller MC, et al. 2020 Incidence of venous thromboembolism in hospitalized patients with COVID-19. J Thromb Haemost 18:1995-2002.

4. Bhatraju PK, Ghassemieh BJ, Nichols M, Kim R, Jerome KR, Nalla AK, et al. 2020 Covid-19 in critically ill patients in the Seattle region-case series. N Engl J Med 382:2012-22.

5. Klok F, Kruip M, Van der Meer N, Arbous M, Gommers D, Kant K, et al. 2020 Incidence of thrombotic complications in critically ill ICU patients with COVID-19. Thromb Res 191:145-7.

6. Perico L, Benigni A, Casiraghi F, Ng LF, Renia L, Remuzzi G. 2020 Immunity, endothelial injury and complement-induced coagulopathy in COVID-19. Nat Rev Nephrol:1-19.

7. Sardu C, Gambardella J, Morelli MB, Wang X, Marfella R, Santulli G. 2020 Hypertension, thrombosis, kidney failure, and diabetes: is COVID-19 an endothelial disease? A comprehensive evaluation of clinical and basic evidence. J Clin Med 9:1417.

8. Varga Z, Flammer AJ, Steiger P, Haberecker M, Andermatt R, Zinkernagel AS, et al. 2020 Endothelial cell infection and endotheliitis in COVID-19. Lancet 395:1417-8.

Fig 1: CT angiography showed thrombotic occlusion at right common iliac artery, right external iliac artery and common femoral artery (blue arrows).

Fig 2: Reconstructed 3D CT angiography show a cut off distal to the common iliac artery (blue arrows). 

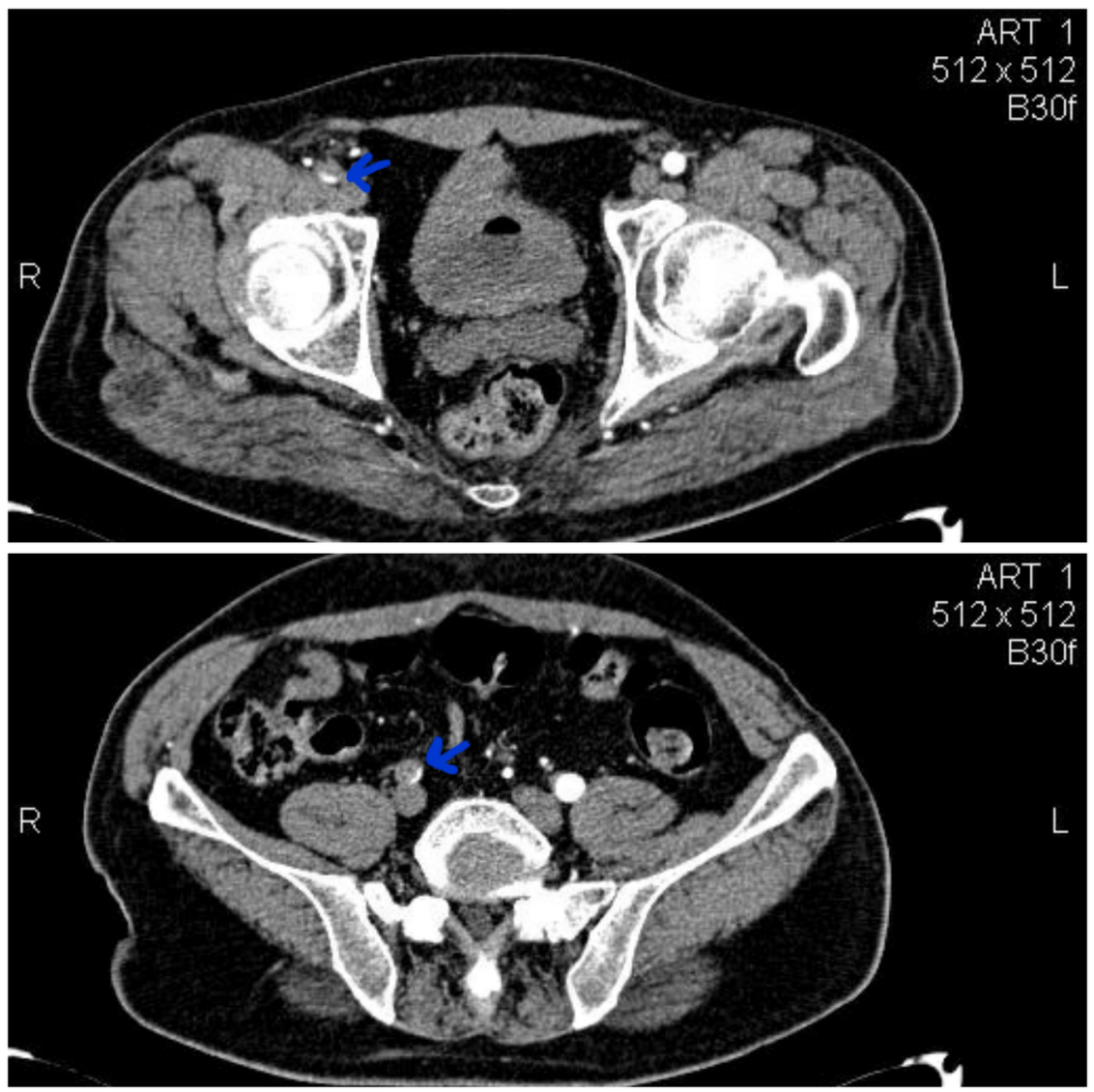

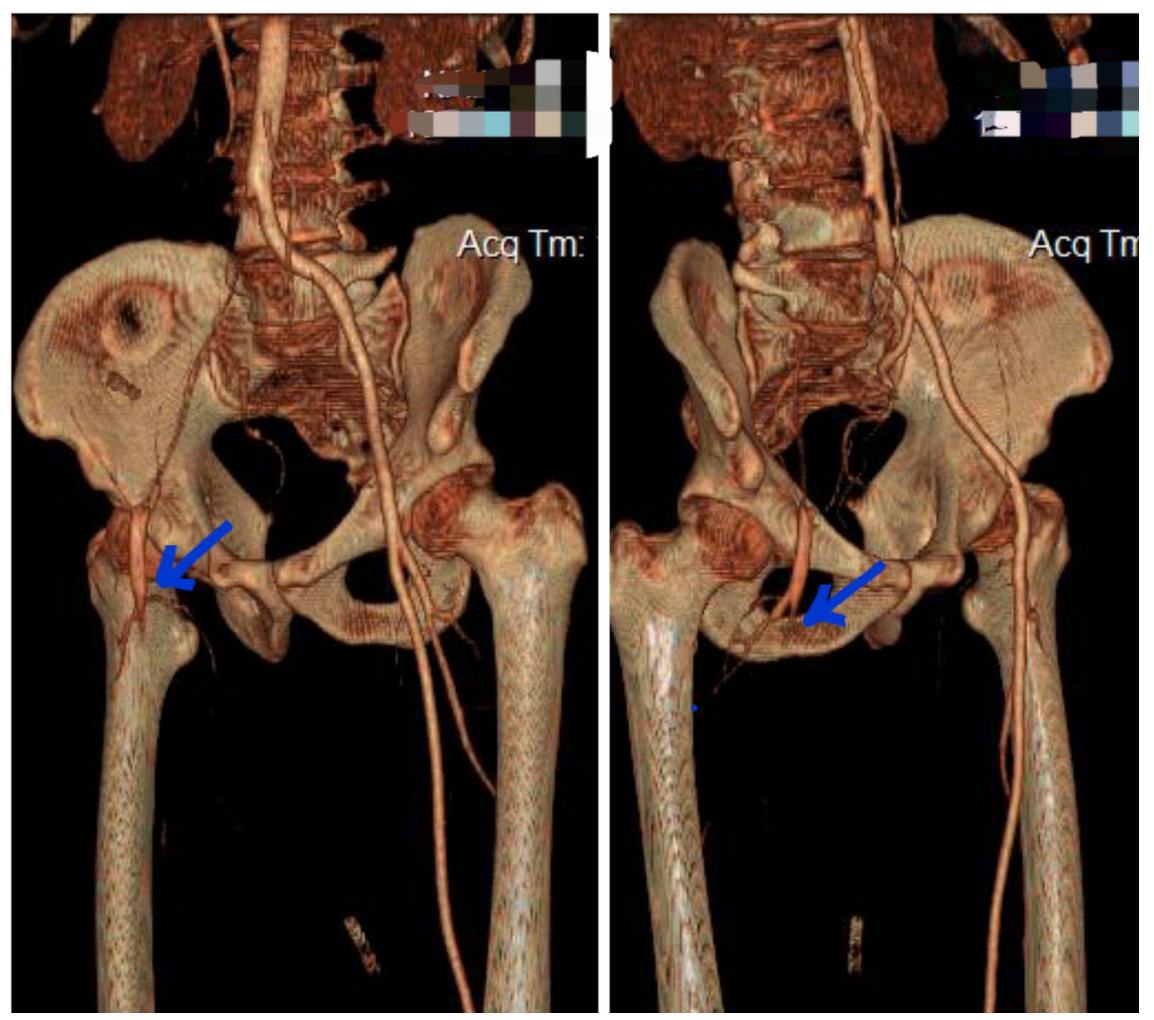